\title{
Synapsin III: Developmental Expression, Subcellular Localization, and Role in Axon Formation
}

\author{
Adriana Ferreira,, ${ }^{1,2}$ Hung-Teh Kao, ${ }^{3,4}$ Jian Feng, ${ }^{3}$ Mark Rapoport, ${ }^{1}$ and Paul Greengard ${ }^{3}$ \\ ${ }^{1}$ Department of Cell and Molecular Biology and 2Institute for Neuroscience, Northwestern University, Chicago, Illinois \\ 60611, 3Laboratory of Molecular and Cellular Neuroscience, The Rockefeller University, New York, New York 10021, and \\ ${ }^{4}$ Department of Psychiatry, New York University Medical Center, New York, New York 10016
}

\begin{abstract}
We have investigated the developmental expression and subcellular localization of synapsin III, the newest member of the synapsin family, in cultured mouse hippocampal neurons. Our results indicate that synapsin III is expressed early during development, with levels peaking $7 \mathrm{~d}$ after plating and declining thereafter. Synapsin III is highly concentrated in growth cones. Using specific antisense oligonucleotides, we have also examined the effect of depleting synapsin III on neurite elongation and synaptogenesis. When synapsin III was suppressed imme-
\end{abstract}

diately after plating, hippocampal neurons extended minor processes but failed to differentiate one of them as the axon. The suppression of synapsin III after axonal elongation did not affect the time course of synapse formation. The results indicate that synapsin III has a developmental time course, a subcellular localization, and a developmental function very different from those of synapsin I and synapsin II.

Key words: synapsin III; neuronal polarity; growth cones; axonal elongation; synaptogenesis; antisense oligonucleotides
The synapsins are a family of neuron-specific phosphoproteins. Two members of this family, synapsin I and synapsin II, were identified almost two decades ago. Distinct genes encode these two synapsins, and their transcripts are alternatively spliced and give rise to two isoforms (Südhof et al., 1989). Both synapsins are highly concentrated at presynaptic nerve terminals in central neurons, are associated with the cytoplasmic surface of synaptic vesicles (DeCamilli et al., 1983, 1988; Finger et al., 1990; Greengard et al., 1993), and play a role in synapse formation. The injection of synapsins into Xenopus blastomeres accelerates synapse formation (Lu et al., 1992; Schaeffer et al., 1994; Valtorta et al., 1995). In addition, the suppression of either synapsin I or synapsin II results in the inhibition of synaptogenesis in hippocampal neurons (Chin et al., 1995; Ferreira et al., 1995, 1996, 1998). Several studies have suggested distinct roles for synapsin I and synapsin II during neuronal development. In cultured hippocampal neurons, synapsin I plays a major role in axonal elongation and branching (Chin et al., 1995), whereas synapsin II plays a major role in the initial elongation of undifferentiated processes (Ferreira et al., 1994, 1998).

Synapsin III, the newest member of the synapsin family, was identified recently. Synapsin III is present in human, mouse, rat (Hosaka and Südhof, 1998; Kao et al., 1998), and Xenopus (Kao et al., 1999) brain and is predominantly expressed in neurons. Analysis of the primary structure of synapsin III indicates that the most conserved domains are A, C, and E, when compared with either synapsin I or synapsin II. In addition, synapsin III, like the other synapsins, is a peripheral membrane protein associated

\footnotetext{
Received Sept. 16, 1999; revised Feb. 22, 2000; accepted March 2, 2000.

This work was supported by the National Alliance for Research on Schizophrenia and Depression Young Investigator Award and Northwestern Institute for Neuroscience start-up funds to A.F. and by National Institutes of Health Grants MH 39327 and AG 15072 to P.G.

Correspondence should be addressed to Dr. Adriana Ferreira, Northwestern Institute for Neuroscience, Searle Building Room 5-474, 320 East Superior Street, Chicago, IL 60611. E-mail: a-ferreira@nwu.edu.

Copyright (c) 2000 Society for Neuroscience 0270-6474/00/203736-09\$15.00/0
}

with synaptic vesicles (Kao et al., 1998). Whether synapsin III plays a role similar to those described for synapsin I and synapsin II during neuronal development was the subject of the present study. We analyzed the developmental expression and subcellular distribution of synapsin III in cultured mouse hippocampal neurons and its role in neurite elongation and synapse formation.

\section{MATERIALS AND METHODS}

Preparation of hippocampal cultures. Neuronal cultures were prepared from the hippocampi of embryonic day 16 mice as described previously (Goslin and Banker, 1991; Chin et al., 1995). Briefly, embryos were removed, and their hippocampi were dissected and freed of meninges. The cells were dissociated by trypsinization $\left(0.25 \%\right.$ for $15 \mathrm{~min}$ at $\left.37^{\circ} \mathrm{C}\right)$ followed by trituration with a fire-polished Pasteur pipette and plated onto poly-L-lysine-coated coverslips in MEM with $10 \%$ horse serum. After $4 \mathrm{hr}$, the coverslips were transferred to dishes containing an astroglial monolayer and maintained in MEM containing N2 supplements (Bottenstein and Sato, 1979) plus ovalbumin (0.1\%) and sodium pyruvate $(0.1 \mathrm{~mm})$. For antisense experiments, the coverslips were transferred, $2 \mathrm{hr}$ after plating, to $35 \mathrm{~mm}$ dishes and incubated in gliaconditioned MEM containing N2 supplements. Sense or antisense oligonucleotides were added directly to the culture medium as described below.

Immunocytochemical procedures. Cultures were fixed for $20 \mathrm{~min}$ with $4 \%$ paraformaldehyde in PBS containing $0.12 \mathrm{M}$ sucrose. They were then permeabilized in $0.3 \%$ Triton X-100 in PBS for 4 min and rinsed twice in PBS. The cells were preincubated in $10 \%$ BSA in PBS for $1 \mathrm{hr}$ at $37^{\circ} \mathrm{C}$ and exposed to the primary antibodies (diluted in 1\% BSA in PBS) overnight at $4^{\circ} \mathrm{C}$. Finally, the cultures were rinsed in PBS and incubated with secondary antibodies for $1 \mathrm{hr}$ at $37^{\circ} \mathrm{C}$. The following antibodies were used: anti-synapsin III [antiserum RU316 (Kao et al., 1998); antiserum RU486], anti- $\alpha$-tubulin (clone DM1A) and polyclonal anti-tubulin (Sigma, St. Louis, MO), anti-synaptophysin (clone SY38; Boehringer Mannheim, Indianapolis, IN), anti-synapsin I [clone 18.1 (Südhof et al., 1989)], anti-synapsin II (clone 19.21), goat anti-mouse IgG fluoresceinconjugated, and goat anti-rabbit IgG rhodamine-conjugated (Boehringer Mannheim). In some experiments, cells exposed to tubulin antibodies were incubated with biotin-conjugated rabbit anti-mouse IgG (Sigma) for $1 \mathrm{hr}$ at room temperature. The coverslips were then washed in PBS and incubated in mouse ExtrAvidin (Sigma) for $1 \mathrm{hr}$ at room temperature. Finally, the coverslips were washed in PBS and incubated in a substrate solution containing $0.05 \%$ 3,3'-diaminobenzidine tetrahydrochloride and 


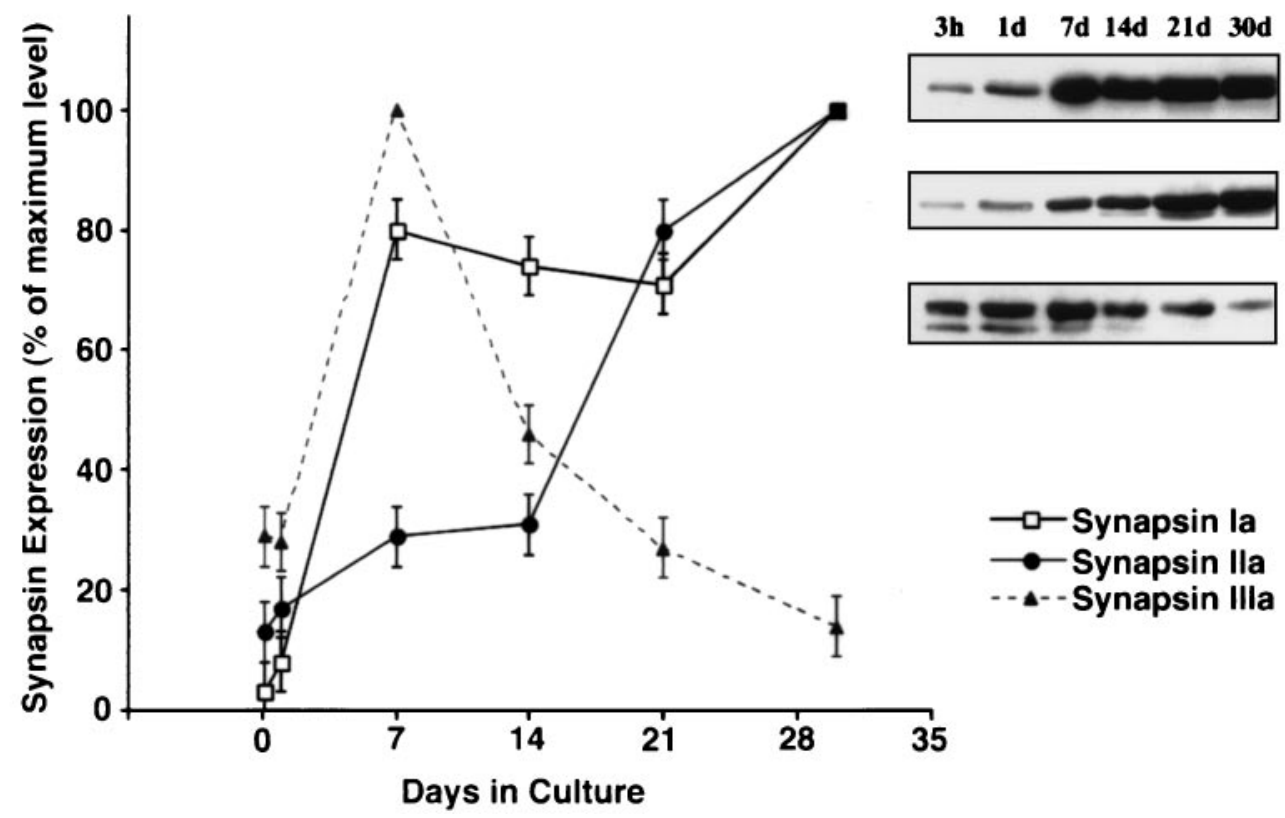

Figure 1. Temporal pattern of expression of the synapsins in cultured hippocampal neurons. Whole-cell extracts were prepared from E16 mouse dissociated hippocampal neurons kept in culture from $3 \mathrm{hr}$ to $30 \mathrm{~d}$. Right, The proteins ( $30 \mu \mathrm{g}$ of total protein/lane) were separated by SDS-PAGE, and immunoblots were reacted with antibodies specific for synapsin I (clone 18.1), synapsin II (clone 19.21), or synapsin III (antiserum RU316). Left, Densitometry of immunoreactive bands was performed, and the results were normalized using tubulin as a control. Values represent means \pm SEM for three experiments. The results are expressed as the percent of the highest level detected.

$0.075 \% \mathrm{H}_{2} \mathrm{O}_{2}(\mathrm{v} / \mathrm{v})$ in $50 \mathrm{~mm}$ Tris, $\mathrm{pH}$ 7.6. The reaction was stopped after sufficient color had developed by immersing the coverslips in deionized water. To visualize growth cones, cells stained with tubulin antibody were counterstained using either rhodamine- or biotin-conjugated phalloidin (Molecular Probes, Eugene, OR).

The specificity of staining was verified by preabsorption of synapsin III antibody (RU316) with an excess of peptide 1322 for $10 \mathrm{hr}$ at $4^{\circ} \mathrm{C}$. Peptide 1322 corresponds to residues 512-530 within domain $\mathrm{J}$ of synapsin III and was used to generate this antibody. Control incubations in which this antibody was preabsorbed with BSA were also performed, showing no change in specific immunoreactivity.

Pictures were taken using TMAX 400 ASA film on a Nikon microscope equipped with a photographic camera. Films were scanned using a Polaroid Sprint SCAN 35 scanner. The acquired digital image files were transferred to a Macintosh G4 Power personal computer, and images were processed using Adobe Photoshop (Adobe Systems, Mountain View, CA) and printed using a Tektronic Phaser II SDX printer.

Antisense oligonucleotides. The initial experiments were performed using the antisense oligonucleotide AS-SIII3 (position -32 to -13 ; 5'-TGGGAATTCTCCTTCCACAC-3') located entirely within the 5'untranslated region. The experiments were repeated using a nonoverlapping oligonucleotide designated AS-SIII9 (position +4 to +23 ; $5^{\prime}$ AGCCGCCTCCGGAGGAAGTT-3'). Position 1 refers to the first nucleotide of the coding sequence of mouse synapsin III (Kao et al., 1999). Both antisense oligonucleotides (Oligos etc., Wilsonville, OR) were S-modified in the last three bases in the $3^{\prime}$-terminal region. For studies before axonogenesis, oligonucleotides were added at a concentration of $50 \mu \mathrm{M}$ every $24 \mathrm{hr}$ to hippocampal neurons that had been maintained in culture for $4 \mathrm{hr}$. For studies before synaptogenesis, oligonucleotides were added at a concentration of $50 \mu \mathrm{M}$ every $24 \mathrm{hr}$ to hippocampal neurons that had been maintained in culture for $4 \mathrm{~d}$. Control cultures were treated with the same concentration of the corresponding sense strand oligonucleotide.

Morphometric analysis. Control and sense- and antisense-treated neurons were fixed at different intervals after plating and stained with tubulin or biotin-conjugated phalloidin (as described above). Cells stained using the tubulin antibody were used to determine total length and the length of minor processes. Cells stained using biotin-conjugated phalloidin were used to determine the growth cone area. Immunoreac- tive processes and growth cones from randomly selected cells were then drawn using a camera lucida, and total neurite length and growth cone area were measured using a digitizing tablet. The proximal limit of the growth cone was defined as the distal part of the neurite where the diameter is twice as big as the neurite itself (Bradke and Dotti, 1997).

All results of the morphometric analysis were expressed as means \pm SEM. Comparisons of the means between groups were made using a paired $t$ test (sense- or antisense-treated vs control samples) and one-way ANOVA followed by a Scheffe test for multiple comparison of means.

Detection of synapses. Synapse formation was determined using synaptophysin and synapsin I as synaptic markers. Images from randomly selected sense- and antisense-treated neurons were acquired at $40 \times$, printed together at the same magnification, and then coded and randomized for blind analysis. The number of synaptophysin- or synapsin I-immunoreactive dots (presynaptic specializations) was determined manually in 150 cells for each experimental condition.

Protein determination, electrophoresis, and immunoblotting. Cultured cells were rinsed twice in warmed PBS, scraped into Laemmli buffer, and homogenized in a boiling water bath for $5 \mathrm{~min}$. After centrifugation, supernatants were removed and stored at $-80^{\circ} \mathrm{C}$ until use. Protein concentration was determined by the method of Lowry et al. (1951) as modified by Bensadoun and Weinstein (1976). SDS-polyacrylamide gels were run according to Laemmli (1970). Transfer of protein to Immobilon membranes (Millipore, Bedford, MA) and immunodetection were performed according to the method of Towbin et al. (1979) as modified by Ferreira et al. (1989). The following antibodies were used: anti- $\alpha$-tubulin (clone DM1A; Sigma), anti-synapsin I (clone 18.1), anti-synapsin II (clone 19.21), and anti-synapsin III (antiserum RU316 and RU486). Secondary HRP-conjugated antibodies (Promega, Madison, WI) followed by enhanced chemiluminescence reagents (Amersham, Arlington Heights, IL) were used. X-ray films were exposed to the immunoblots and analyzed using a Bio-Rad 700 flatbed scanner (Bio-Rad, Hercules, CA) and Molecular Analyst software (Bio-Rad). Films were scanned at 600 dpi using light transmittance, and volume analysis was performed on the appropriate bands. The lower band was included in the quantification of synapsin IIIa. Films were analyzed after different exposure times to ensure the accuracy of quantitation. Densitometric values were normalized using $\alpha$-tubulin present in the extracts. 

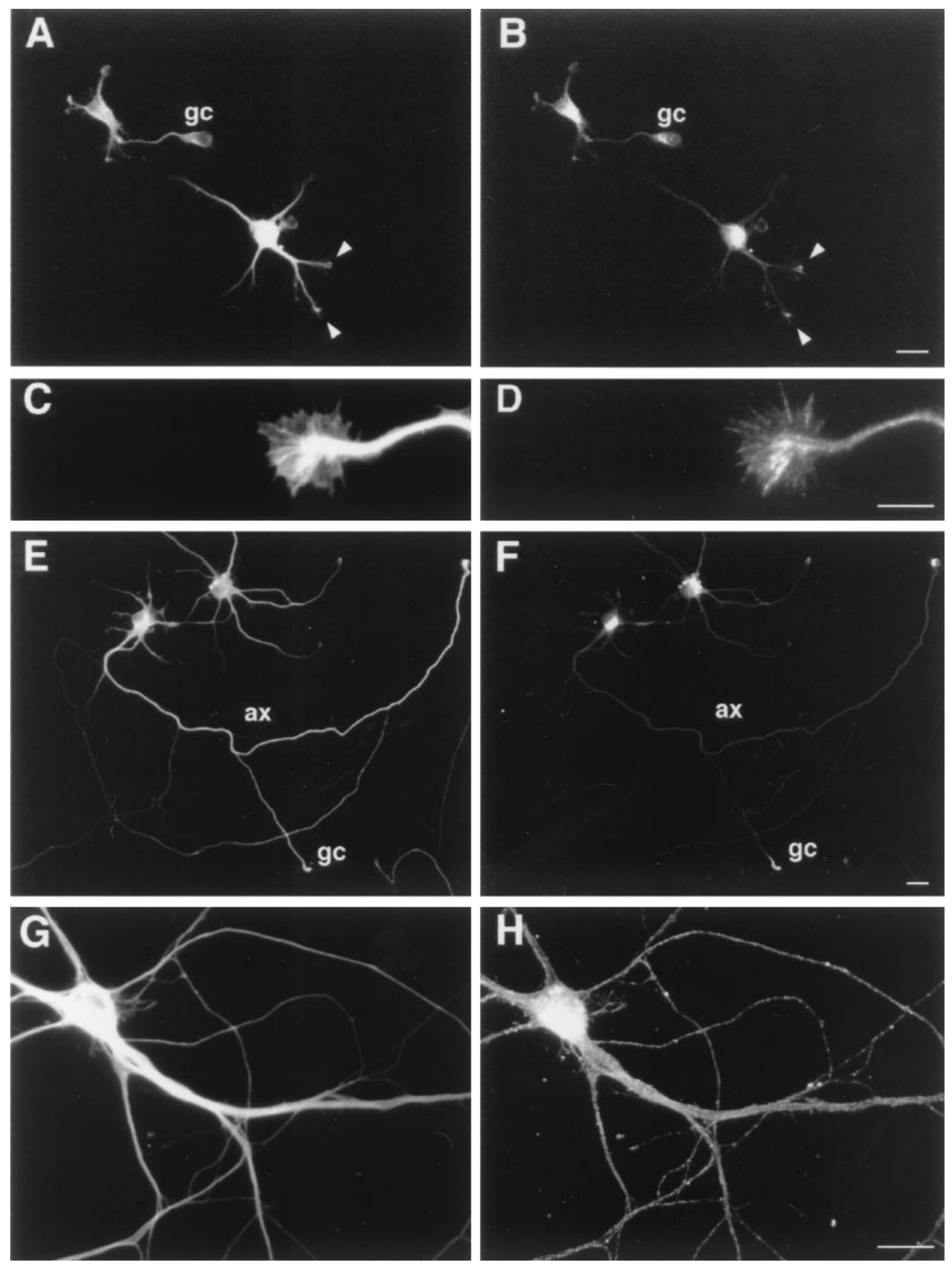

Figure 2. Localization of synapsin III in developing hippocampal neurons. Hippocampal neurons were fixed $8 \mathrm{hr}$ (stage II; $A, B$, low magnification; $C$, $D$, high magnification), $1 \mathrm{~d}$ (stage III; $E, F$ ), and $7 \mathrm{~d}$ (stage IV; $G, H$ ) after plating and double stained using tubulin $(A, C, E$, $G)$ and synapsin III (antiserum RU316; $B, D, F, H$ ) antibodies. Synapsin III immunoreactivity was concentrated in cell bodies and growth cones ( $g c$; arrowheads) in stage II and stage III cells. In stage IV cells $(H)$, a fine puncta of immunoreactive material was detected along the processes. $a x$, Axon. Scale bars: $A$, $B$, 20 $\mu \mathrm{m} ; C, D, 20 \mu \mathrm{m} ; E, F, 20 \mu \mathrm{m} ; G, H, 20 \mu \mathrm{m}$.

\section{RESULTS}

\section{Developmental expression of synapsin III in cultured hippocampal neurons}

Immunoblots were prepared from cells kept in culture for various intervals and reacted with specific anti-synapsin III antibodies
(RU316 and RU486). The two antibodies tested gave virtually identical results and recognized a major band at $63 \mathrm{kDa}$ corresponding to synapsin IIIa (Kao et al., 1998). Levels of synapsin III increased with development in culture, reached their peak at $7 \mathrm{~d}$ after plating, and decreased thereafter (Fig. 1). The pattern of expression of synapsin III contrasted with those of synapsin I and 

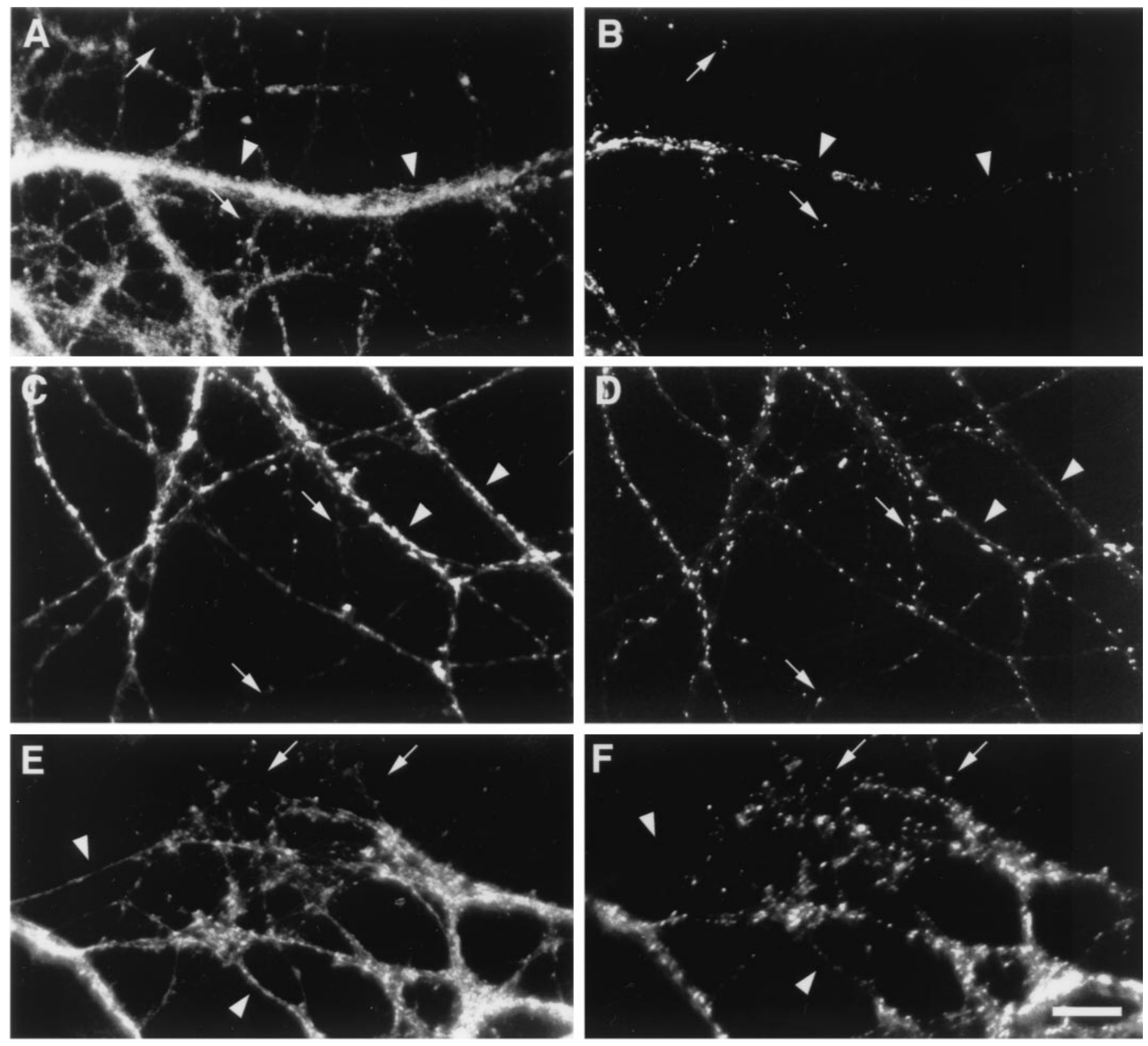

Figure 3. Comparison of the localization of synapsin III with that of synaptic markers in cultured hippocampal neurons. After $7 \mathrm{~d}$ in culture, hippocampal neurons were fixed and double stained with synapsin III $(A, C, E)$ and synaptophysin $(B)$, synapsin I $(D)$, or synapsin II $(F)$ antibodies. Synapsin III immunoreactivity failed to colocalize at synaptic sites with any of the synaptic markers used. Arrows point to synaptic sites $(B, D, F)$ devoid of synapsin III $(A, C, E)$. Arrowheads point to extrasynaptic sites rich in synapsin III $(A, C, E)$ and devoid of synaptophysin $(B)$, synapsin I $(D)$, or synapsin II $(F)$. Scale bar, $10 \mu \mathrm{m}$.

synapsin II. Both of these proteins continued to increase in amount as the cells developed in culture (Fig. 1).

\section{Localization of synapsin III in cultured hippocampal neurons}

When placed in culture hippocampal neurons extend and differentiate axons and dendrites following a sequence of well defined morphological changes (Dotti et al., 1988). Hippocampal neurons, initially round and surrounded by lamellipodial veils (stage I), extend undifferentiated minor processes as soon as $4 \mathrm{hr}$ after plating (stage II). One day after plating the cells extend an axon and several short minor processes (stage III) that will differentiate into dendrites $4 \mathrm{~d}$ later (stage IV). Synaptic contacts are estab- lished 5-7 d after plating (Fletcher et al., 1991). Synapsin III was detected in hippocampal neurons from the beginning of their morphological differentiation. In stage I (data not shown) and stage II and stage III (Fig. 2) cells, synapsin III was concentrated in all cell bodies and in $\sim 75 \%$ of growth cones. In stage III cells, very faint immunoreactivity for synapsin III was also detected along the axon. In mature hippocampal neurons (stage IV-V cells), synapsin III immunoreactivity could be detected as fine puncta along the axon (Fig. 2). Occasionally, large immunoreactive axonal spots were detected.

Double-staining experiments were performed to determine whether synapsin III was present at synaptic contacts. Synapto- 


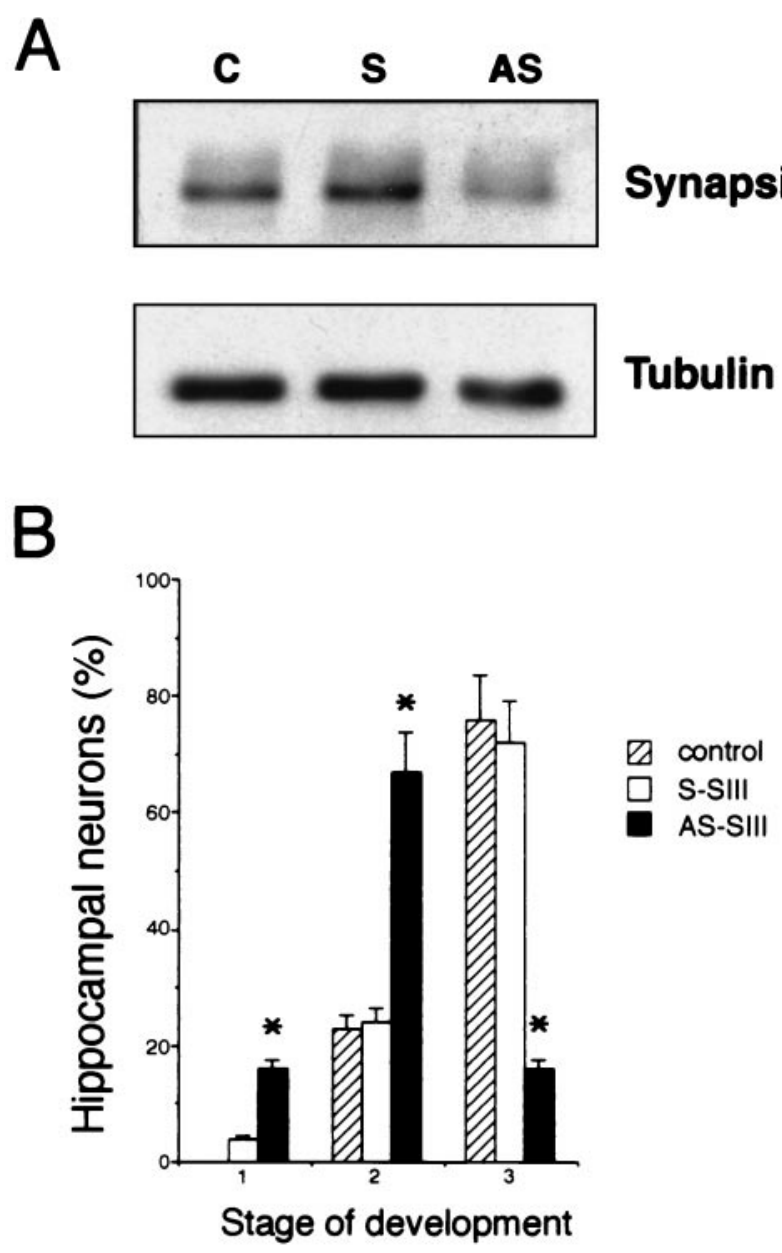

C

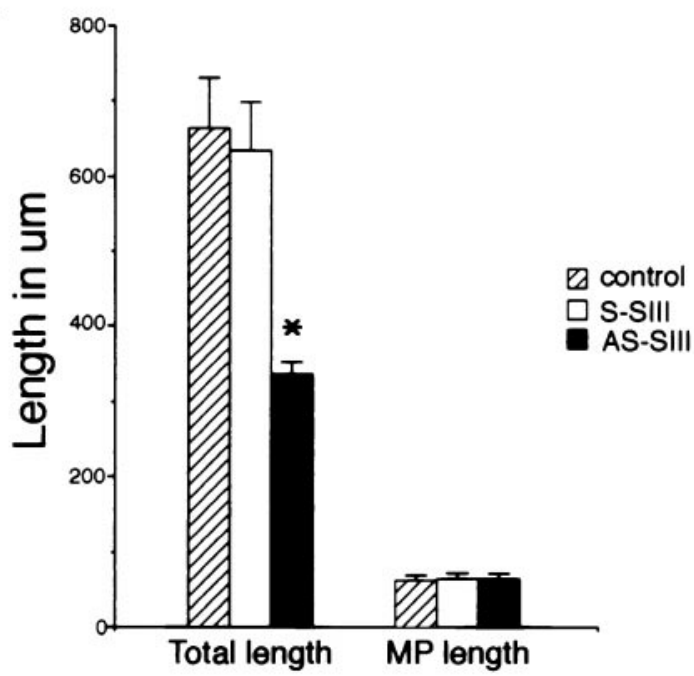

Figure 4. Effect of synapsin III antisense oligonucleotides on cultured hippocampal neurons. $A$, Western blot analysis of synapsin III and tubulin expression in control $(C)$ and sense $(S)$ - and antisense $(A S)$-treated neurons kept in culture for $24 \mathrm{hr} . B, C$, Graphs showing the stage of development $(B)$ and the total length and length of minor processes $(C)$ of control and sense- and antisense-treated hippocampal neurons kept in culture for $2 \mathrm{~d}$. Cells stained with tubulin using the DAB method were used for this morphometric analysis. For quantification purposes cells were considered to be in stage 3 when one of the processes was at least 20 $\mu \mathrm{m}$ longer than the rest of the processes. Values represent means $\pm \mathrm{SEM}$. physin, synapsin I, and synapsin II were used as synaptic markers. In cultured hippocampal neurons, the localization of these proteins at synapses has been confirmed at the ultrastructural level (Fletcher et al., 1991; Ferreira et al., 1995). Although some synapsin III-immunoreactive spots colocalized with synaptophysin, synapsin I, or synapsin II, most of the immunoreactivity for synapsin III was localized at extrasynaptic sites (Fig. 3).

\section{Phenotype of synapsin III-depleted hippocampal neurons}

The localization of synapsin III to growth cones suggested the possibility of a role for synapsin III in axonal elongation and/or synapse formation. To evaluate this possibility, we suppressed synapsin III expression by culturing hippocampal neurons in the presence of antisense oligonucleotides. Two nonoverlapping 20 mer oligonucleotides were designed based on the mouse synapsin III sequence (Kao et al., 1999) and added at a final concentration of $50 \mu \mathrm{M}$. To suppress the expression of synapsin III before axonal elongation, oligonucleotides were added to 4-hr-old cultures, and cells were analyzed 24 and 48 hr later. Both antisense oligonucleotides (designated AS-SIII3 and AS-SIII9) reduced the levels of synapsin III by $75-80 \%$ when compared with sense-treated or nontreated control cells at $24 \mathrm{hr}$ (Fig. 4A) and $48 \mathrm{hr}$ (data not shown).

Synapsin III-depleted hippocampal neurons displayed an abnormal morphology during their initial phases of development (Figs. 4, 5). No differences were detected in the number, morphology, and length of minor processes as compared with sensetreated or nontreated control cells. In contrast, axonal differentiation was impaired (Fig. $4 \mathrm{C}$ ). More than $80 \%$ of the synapsin III-depleted hippocampal neurons failed to elongate their axons 24 or $48 \mathrm{hr}$ after plating (Figs. $4 B, 5$ ). The lack of axonal differentiation in synapsin III-depleted neurons resulted in a significant decrease in total neurite length when compared with untreated controls or sense-treated cells (Fig. 4C). The impaired axonal elongation observed in synapsin III-depleted cells was accompanied by changes in the growth cones. A significant increase in the size of the growth cones was detected in synapsin III-depleted neurons $24 \mathrm{hr}$ (46\% increase) and $48 \mathrm{hr}$ (51\% increase) after plating when compared with controls (Fig. 6).

To determine whether synapse formation occurs in the absence of synapsin III, cells were allowed to grow for $4 \mathrm{~d}$ and then were treated with $50 \mu \mathrm{M}$ sense or antisense synapsin III oligonucleotides every $24 \mathrm{hr}$. Either antisense synapsin III oligonucleotide (AS-SIII3 and AS-SIII9) reduced the amount of synapsin III by $\sim 80 \%$ as determined by Western blot analysis. The presence of synaptic contacts in control and sense- and antisense-treated neurons was determined, 24 and $72 \mathrm{hr}$ after the addition of the antisense oligonucleotide, using synaptophysin as a synaptic marker (Fig. 7). Synapses were detected as early as $5 \mathrm{~d}$ after plating in both sense- and antisense-treated cultures. Thus, the time course of synapse formation was not altered in synapsin III-depleted neurons when compared with sense-treated or nontreated controls. We also determined the number of synapses in sense- and antisense-treated cultures double stained with tubulin and synaptophysin antibodies. No significant differences in the number of synapses were detected after $7 \mathrm{~d}$ in culture in synapsin

A total of 90 cells from three different experiments were analyzed for each experimental condition. *, Differs from control or sense-treated cells $(\mathrm{p}<$ 0.001; ANOVA). MP, Minor processes; SIII, synapsin III. 

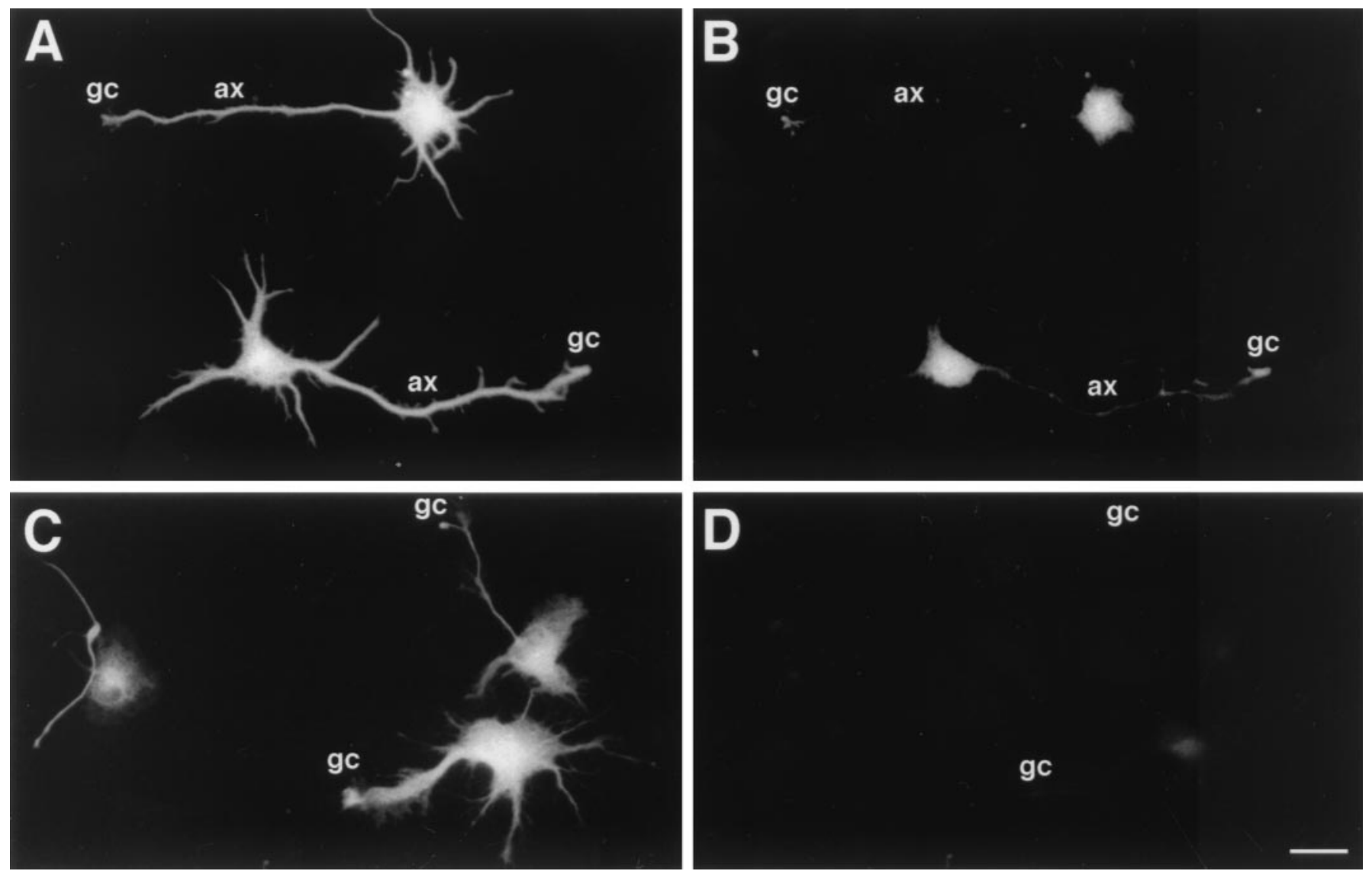

Figure 5. Phenotype of synapsin III-depleted hippocampal neurons. After $2 \mathrm{~d}$ in culture, sense $(A, B)$ - and antisense $(C, D)$-treated cells were fixed and double stained with tubulin $(A, C)$ and synapsin III $(B, D)$ antibodies. Synapsin III immunoreactivity was detectable along the axons $(a x)$ and was highly concentrated in cell bodies and growth cones $(g c)$ in sense-treated neurons. Note the absence of synapsin III immunoreactivity in synapsin III antisense-treated neurons. Scale bar, $20 \mu \mathrm{m}$.

III-depleted neurons when compared with sense-treated controls ( $30 \pm 5$ vs $37 \pm 4$ synapses/cell, respectively; $n=150$ cells from three independent experiments). Similar results were obtained when synapses were counted in sense- and antisense-treated cultures double stained with tubulin and synapsin I antibodies (42 \pm 7 vs $50 \pm 4$ synapses/cell, respectively; $n=150$ cells from three independent experiments).

Finally, we considered the possibility that the effect of synapsin III depletion might be attributable in part to a decrease in the expression of the other known members of the synapsin family. No significant changes in synapsin I $(89 \pm 8 \%)$ or synapsin II $(92 \pm 10 \%)$ levels were detected in antisense synapsin III-treated neurons when compared with control cells.

\section{DISCUSSION}

The present findings provide strong evidence of a distinct role for synapsin III, the most recently discovered member of the synapsin family, in the establishment of neuronal polarity in central neurons. The predominant expression of synapsin III during the early stages of development, as well as its subcellular localization at extrasynaptic sites, distinguishes synapsin III from the other members of the synapsin family. Although the levels of synapsin I and synapsin II correlate with the extent of synapse formation both in situ and in culture (Lohmann et al., 1978; Goelz et al., 1981) (this study), the highest levels of synapsin III are detected during the first week in culture, a period that corresponds to active process elongation. Consistent with a role in neurite out- growth, synapsin III is highly enriched in growth cones in cultured hippocampal neurons. This localization contrasts with that of synapsin I and synapsin II, which are detected in minor processes and the distal third of the axon in developing neurons. The preferential localization of synapsin III in growth cones prompted us to perform experiments to determine the role of this protein during neurite elongation and the establishment of polarity in cultured hippocampal neurons. We used primary hippocampal cultures because (1) they represent a relatively homogeneous population of neurons and (2) they differentiate in a reproducible manner via a series of well characterized morphological changes (Dotti et al., 1988). Immediately after dissociation, neurons are round and partially or totally surrounded by lamellipodial veils (stage I). The consolidation of these veils into short and undifferentiated processes (stage II) takes place as early as $4 \mathrm{hr}$ after plating. These processes show no net elongation for almost a day, at which time one of them begins to elongate at a rapid rate and becomes the axon (stage III). We have shown previously that this sequence of events is altered by the suppression of either synapsin I or synapsin II. Synapsin II suppression impaired the normal elongation of minor processes and, therefore, the transition between stage I and stage II (Ferreira et al., 1994, 1998). On the other hand, the suppression of synapsin I resulted in well differentiated axons, albeit shorter and less branched ones than those observed in wild-type cells (Chin et al., 1995). Our results indicate that hippocampal neurons depleted of 

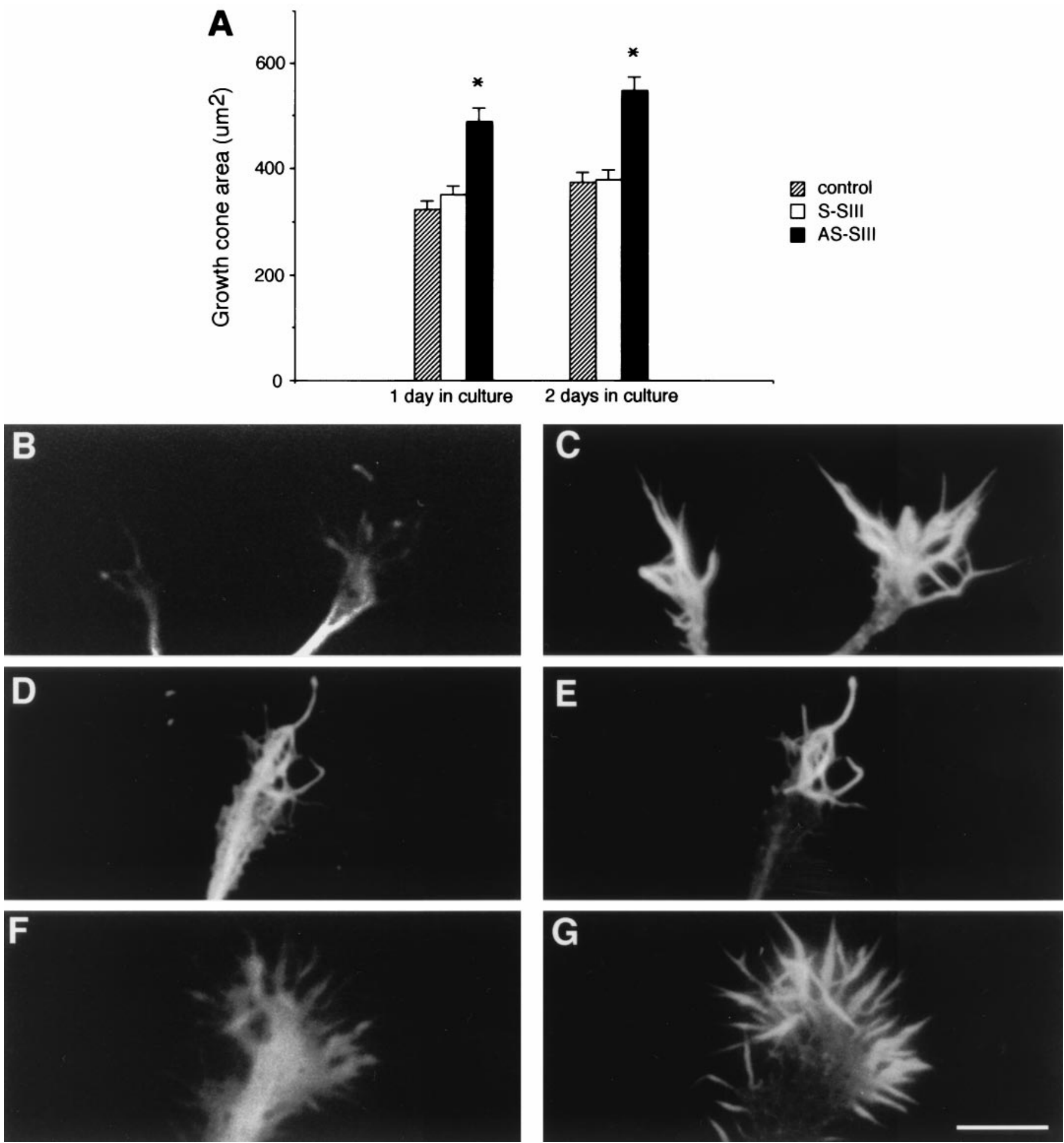

Figure 6. Suppression of synapsin III resulted in a changed appearance of growth cones. $A$, Graph showing the area of growth cones in control and sense $(S)$ - and antisense $(A S)$-treated hippocampal neurons kept in culture for 1 and $2 \mathrm{~d}$. Values represent the means \pm SEM. A total of 90 growth cones from three different experiments were analyzed for each experimental condition. *, Differs from control or sense-treated cells $(p<0.01$; ANOVA). SIII, Synapsin III. $B-G$, Representative growth cones from control $(B, C)$ and sense $(D, E)$ - and antisense $(F, G)$-treated neurons. The cells were fixed, stained with a tubulin antibody $(B, D, F)$, and counterstained using rhodamine-phalloidin $(C, E, G)$. Scale bar, $10 \mu \mathrm{m}$.

synapsin III are capable of extending normal minor processes but fail to elongate and differentiate their axons (transition between stage II and stage III). This impairment in axonal differentiation is accompanied by a significant enlargement of the growth cones. It has been suggested that the differentiation of one minor process into an axon is preceded by the enlargement of its growth cone (Bradke and Dotti, 1997). The enlargement of a growth cone presumably results from an increase in membrane addition because of a selected trafficking of organelles toward the tip of the process that will elongate as an axon. The impairment of axonal 

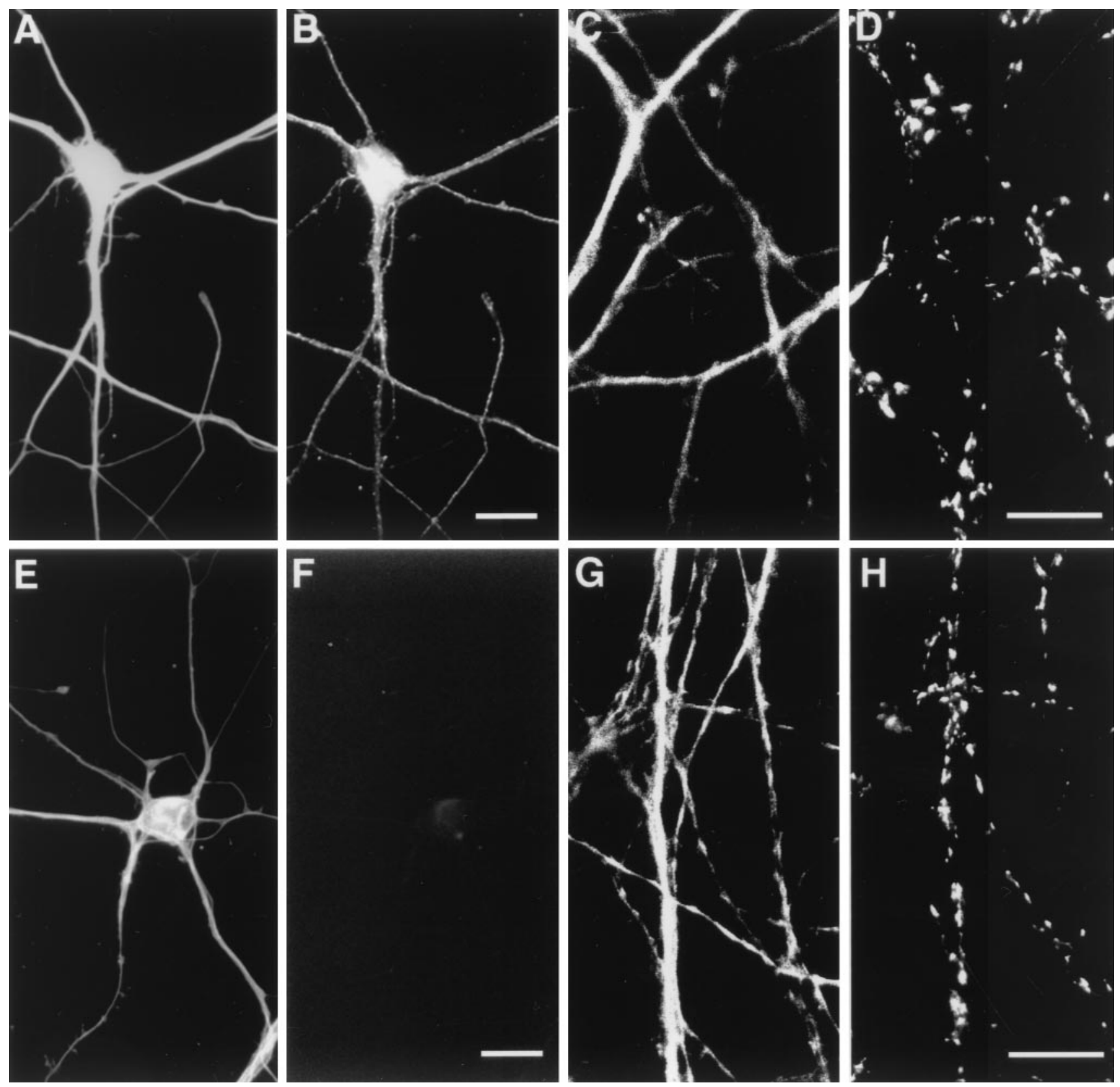

Figure 7. Synapse formation in synapsin III-depleted hippocampal neurons. After $4 \mathrm{~d}$ in culture, neurons were treated for $72 \mathrm{hr}$ with sense $(A-D)$ or antisense $(E-H)$ oligonucleotides and analyzed by double staining with tubulin $(A, E)$ and synapsin III $(B, F)$ antibodies or tubulin $(C$, $G)$ and synaptophysin $(D, H)$ antibodies. Note the presence of synapses in both sense $(D)$ - and antisense $(H)$-treated neurons. Scale bars: $A, B, 20 \mu$ m; $C, D$, $20 \mu \mathrm{m} ; E, F, 20 \mu \mathrm{m} ; G, H, 20 \mu \mathrm{m}$.

elongation by synapsin III suppression in a cell in which the rate of trafficking of material to growth cones is not affected could result in the abnormal accumulation of material and, hence, in an increase in the size of the growth cones.

Changes not only in the size of the growth cone but also in the dynamics of its cytoskeleton precede axonal differentiation (Bradke and Dotti, 1999). It has been suggested that the local instability of actin filaments in a given growth cone could act as a physiological signal triggering axonal differentiation (Bradke and Dotti, 1999). We could speculate that the lack of synapsin III in growth cones alters actin dynamics, preventing axonal elongation. Other members of the synapsin family have been implicated in the polymerization and bundling of actin filaments (Baines and
Bennett, 1986; Petrucci and Morrow, 1991; Chilcote et al., 1994). Although no direct evidence is available regarding the interaction of synapsin III with actin, its high degree of homology (Kao et al., 1998) with the actin-binding domain of synapsin I (Bähler et al., 1989) suggests that synapsin III also plays a role in the organization of the actin cytoskeleton.

The suppression of synapsin III after axonal elongation but before synaptogenesis did not alter the time course of synapse formation in cultured hippocampal neurons. The lack of a prominent role for synapsin III in synapse formation is consistent with its paucity at synaptic sites. Synapsin III is present at much lower levels in nerve terminals than are synapsin I and synapsin II, which are required for synapse formation in cultured hippocam- 
pal neurons. The suppression of synapsin I or synapsin II by either antisense oligonucleotides or homologous recombinant techniques results in a delay in synapse formation (Chin et al., 1995; Ferreira et al., 1995, 1996; Li et al., 1995; Rosahl et al., 1995; Takei et al., 1995). Although the present results argue against an important role for synapsin III in synapse formation, its involvement in synaptogenesis cannot be excluded because biochemical studies indicate that synapsin III is associated with synaptic vesicles, although at a much lower level than are synapsins I and II (Kao et al., 1998).

The data presented here indicate that synapsin III has a role during neuronal development distinct from those of synapsins I and II. Further analyses should provide additional insights into the participation of synapsin III in the mechanisms underlying axonal differentiation in central neurons.

\section{REFERENCES}

Bähler M, Benfenati F, Valtorta F, Czernik AJ, Greengard P (1989) Characterization of synapsin I fragments produced by cysteine-specific cleavage: a study of their interactions with F-actin. J Cell Biol 108:1841-1849.

Baines AJ, Bennett V (1986) Synapsin I is a microtubule-bundling protein. Nature 319:145-147.

Bensadoun A, Weinstein R (1976) Assay of protein in the presence of interfering material. Anal Biochem 70:241-250.

Bottenstein JE, Sato GH (1979) Growth of a rat neuroblastoma cell line in serum-free supplemented media. Proc Natl Acad Sci USA 76:514-517.

Bradke F, Dotti CG (1997) Neuronal polarity: vectorial cytoplasmic flow precedes axon formation. Neuron 19:1175-1186.

Bradke F, Dotti CG (1999) The role of local actin instability in axon formation. Science 283:1931-1934.

Chilcote TJ, Siow YL, Schaeffer E, Greengard P, Thiel G (1994) Synapsin IIa bundles actin filaments. J Neurochem 63:1568-1571.

Chin LS, Li L, Ferreira A, Kosik KS, Greengard P (1995) Impairment of axonal development and of synaptogenesis in hippocampal neurons of synapsin I-deficient mice. Proc Natl Acad Sci USA 92:9230-9234.

DeCamilli P, Cameron P, Greengard P (1983) Synapsin I (protein I), a nerve terminal-specific phosphoprotein. I. Its general distribution in synapses of the central and peripheral nervous system demonstrated by immunofluorescence in frozen and plastic sections. J Cell Biol 96:1337-1354.

DeCamilli P, Vidatello M, Canevini M, Zanoni R, Jahn R, Gorio A (1988) The synaptic vesicle proteins synapsin I and synaptophysin (protein P38) are concentrated in both efferent and afferent nerve endings of the skeletal muscle. J Neurosci 8:1625-1631.

Dotti CG, Sullivan CA, Banker GA (1988) The establishment of polarity by hippocampal neurons in culture. J Neurosci 8:1454-1468.

Ferreira A, Busciglio J, Caceres A (1989) Microtubule formation and neurite growth in cerebellar macroneurons which develop in vitro: evidence for the involvement of the microtubule-associated proteins, MAP-1a, HMW-MAP-2 and tau. Dev Brain Res 49:215-228.

Ferreira A, Kosik KS, Greengard P, Han HQ (1994) Aberrant neurites and synaptic vesicle protein deficiency in synapsin II-depleted neurons. Science 264:977-979.

Ferreira A, Han HQ, Greengard P, Kosik KS (1995) Suppression of synapsin II inhibits the formation and maintenance of synapses in hippocampal culture. Proc Natl Acad Sci USA 92:9225-9229.

Ferreira A, Li L, Chin LS, Greengard P, Kosik KS (1996) Postsynaptic element contributes to the delay in synaptogenesis in synapsin I deficient neurons. Mol Cell Neurosci 8:286-299.
Ferreira A, Chin LS, Li L, Lanier LM, Kosik KS, Greengard P (1998) Distinct roles of synapsin I and synapsin II during neuronal development. Mol Med 4:22-28.

Finger TE, Womble M, Kinamon JC, Ueda T (1990) Synapsin I-like immunoreactivity in nerve fibers associated with lingual taste buds of the rat. J Comp Neurol 292:283-290.

Fletcher TP, Cameron P, De Camilli P, Banker GA (1991) The distribution of synapsin I and synaptophysin in hippocampal neurons in culture. J Neurosci 11:1617-1632.

Goelz SE, Nestler EJ, Chehrazi B, Greengard P (1981) Distribution of protein $\mathrm{I}$ in mammalian brain as determined by a detergent-based radioimmunoassay. Proc Natl Acad Sci USA 78:2130-2134.

Goslin K, Banker GA (1991) Hippocampal neurons in low density culture. In: Culturing nerve cells (Banker GA, Goslin K, eds), pp 251-283. Cambridge, MA: MIT.

Greengard P, Valtorta F, Czernik AJ, Benfenati F (1993) Synaptic vesicle phosphoproteins and regulation of synaptic function. Science 259:780-785.

Hosaka M, Südhof TC (1998) Synapsin III, a novel synapsin with an unusual regulation by $\mathrm{Ca}^{2+}$. J Biol Chem 273:13371-13374.

Kao H-T, Porton B, Czernik AJ, Feng J, Yiu G, Häring M, Benfenati F, Greengard P (1998) A third member of the synapsin gene family. Proc Natl Acad Sci USA 95:4667-4672.

Kao H-T, Porton B, Hilfiker S, Stefani G, DeSalle R, Pieribone VA, Greengard P (1999) Molecular evolution of the synapsin gene family. J Exp Zool 285:360-377.

Laemmli UK (1970) Cleavage of structural protein during the assembly of the head of the bacteriophage T4. Nature 227:680-685.

Li L, Chin L, Shupliakov O, Brodin L, Sihra T, Hvalby Ø, Jensen V, Zieng D, McNamara JO, Greengard P, Andersen P (1995) Impairment of synaptic vesicle clustering and of synaptic transmission, and increased seizure propensity, in synapsin I-deficient mice. Proc Natl Acad Sci USA 92:9235-9239.

Lohmann SM, Ueda T, Greengard P (1978) Ontogeny of synaptic phosphoproteins in brain. Proc Natl Acad Sci USA 75:4037-4041.

Lowry OH, Reserbrough NJ, Farr AL, Randall RJ (1951) Protein measurements with the folin phenol reagents. J Biol Chem 193:265-275.

Lu B, Greengard P, Poo M-m (1992) Exogenous synapsin I promotes functional maturation of developing neuromuscular synapses. Neuron 8:521-529.

Petrucci TC, Morrow JF (1991) Synapsin I: an actin-bundling protein under phosphorylation control. Biochemistry 30:413-422.

Rosahl TW, Spillane D, Missler M, Herz J, Selig D, Wolff JR, Hammer RE, Malenka RC, Südhof TC (1995) Essential functions of synapsin I and II in synaptic vesicle regulation. Nature 375:488-493.

Schaeffer E, Alder J, Greengard P, Poo M-m (1994) Exogenous synapsin I promotes functional maturation of developing neuromuscular synapses. Proc Natl Acad Sci USA 91:3882-3886.

Südhof TC, Czernik AJ, Kao H-T, Takei K, Johnston PA, Horiuchi A, Wagner M, Kanazir SD, Perin MS, De Camilli P, Greengard P (1989) Synapsins: mosaic of shared and individual domains in a family of synaptic vesicle phosphoproteins. Science 245:1474-1480.

Takei Y, Harada A, Takeda S, Kobayashi K, Terada S, Noda T, Takahashi T, Hirokawa N (1995) Synapsin I deficiency results in the structural change in the presynaptic terminals in the murine nervous system. J Cell Biol 131:1789-1800.

Towbin H, Staehelein T, Gordon J (1979) Electrophoretic transfer of protein from polyacrylamide gels to nitrocellulose sheets: procedure and some applications. Proc Natl Acad Sci USA 76:4354-4356.

Valtorta F, Iezzi N, Benfenati F, Lu B, Poo M-m, Greengard P (1995) Accelerated structural maturation induced by synapsin I at developing neuromuscular synapses of Xenopus laevis. Eur J Neurosci 7:261-270. 